\title{
Lobectomy with high-position single-intercostal two-port video- assisted thoracoscope for non-small cell lung cancer is a safe and effective surgical procedure
}

\author{
Guofang Zhao $^{1 \#}$, Xu Jiang ${ }^{1 \#}$, Fajiu Wang ${ }^{1}$, Minghui Chu ${ }^{2}$, Chenxu Zhang ${ }^{2}$, Weidi Zhao ${ }^{2}$, Minglei Yang ${ }^{1}$, \\ Xiang $\mathrm{Xu}^{1}$, Enkuo Zheng ${ }^{1}$, Junjun $\mathrm{Ni}^{1}$, Liangwei Yang ${ }^{1}$ \\ ${ }^{1}$ Department of Cardiothoracic Surgery, Hwa Mei Hospital, University of Chinese Academy of Sciences (Ningbo No. 2 Hospital), Ningbo, China; \\ ${ }^{2}$ Clinical Department, Medical School of Ningbo University, Ningbo, China \\ Contributions: (I) Conception and design: G Zhao; (II) Administrative support: X Jiang, F Wang; (III) Provision of study materials or patients: M \\ Chu, C Zhang, W Zhao; (IV) Collection and assembly of data: M Yang, X Xu; (V) Data analysis and interpretation: E Zheng, J Ni, L Yang; (VI) \\ Manuscript writing: All authors; (VII) Final approval of manuscript: All authors. \\ "These authors contributed equally to this work. \\ Correspondence to: Guofang Zhao. Department of Cardiothoracic Surgery, Hwa Mei Hospital, University of Chinese Academy of Sciences (Ningbo \\ No. 2 Hospital), Ningbo, China. Email: guofzhao@hotmail.com.
}

Background: High-position single-intercostal two-port video-assisted thoracic surgery (VATS) technique has been used for thoracic diseases. It can effectively avoid postoperative chronic pain compared with the traditional three-port VATS. This study aimed to evaluate the safety and efficacy of high-position singleintercostal two-port video-assisted thoracoscopic lobectomy.

Methods: From June 2014 to December 2018, a total of 474 patients in our hospital with non-small cell lung cancer (NSCLC) underwent lobectomy with a high-position single-intercostal two-port video-assisted thoracoscope. A retrospective study of these patients was conducted, and follow-up was performed to analyze the patients' 3 - and 5-year survival rates.

Results: Of the total number of patients, $27.6 \%, 41.4 \%$, and $31 \%$ underwent surgery between the third, fourth, and fifth intercostals, respectively. During the operation, 31 patients were converted to open surgery or three-port thoracoscopic surgery. The average surgical time was $160.9 \pm 44.9 \mathrm{~min}$, the average postoperative hospital stay was $5.6 \pm 3.4$ days, the incidence of postoperative complications was $7.2 \%$, and

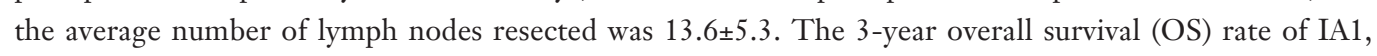
IA2, IA3, IB, IIA, IIB and IIIA was $99.0 \%, 98.6 \%, 96.3 \%, 91.2 \%, 85.7 \%, 66.7 \%$, and 60.8\%, respectively. Meanwhile, the 5-year OS rate of IA1, IA2, IA3, IB, and IIIA was $99.0 \%, 94.5 \%, 87.5 \%, 85.5 \%$, and $43.3 \%$, respectively.

Conclusions: Lobectomy with a high-position single-intercostal two-port video-assisted thoracoscope for NSCLC is a safe and effective surgical procedure.

Keywords: Video-assisted thoracoscopic surgery (VATS); two-port; non-small cell lung cancer (NSCLC); lobectomy; safety; efficacy

Submitted Oct 28, 2020. Accepted for publication Dec 17, 2020.

doi: $10.21037 /$ jtd-20-3469

View this article at: http://dx.doi.org/10.21037/jtd-20-3469 


\section{Introduction}

Lung cancer is one of the most common malignancies and is the leading cause of cancer-related mortality worldwide. Most lung cancer cases have been attributed to nonsmall cell lung cancer (NSCLC), which includes different histological types such as lung adenocarcinoma, squamous cell carcinoma, and large cell lung cancer. Video-assisted thoracoscopic surgery (VATS) is a procedure performed without the ribs being propped open, operating only with a television display (1). In recent years, it has been widely used in lobectomy for NSCLC (2-4). In traditional VATS lobectomy, the 7 th or 8 th intercostal aperture is selected as the mirror observation port, and 1-3 intercostal operational ports are added to the $3 \mathrm{rd}-6$ th intercostal cavity $(4,5)$. However, several years after surgery, some patients still complain of chest wall pain at the surgical site $(6,7)$. According to the Macrae description criteria (8), postoperative pain that lasts for more than two months is classified as postoperative chronic pain. Intercostal nerve injury is considered to be the leading cause of chronic pain after thoracic surgery. Since the incision only affects one intercostal nerve, single-port thoracoscopic surgery has the potential advantage of avoiding postoperative chronic pain in patients compared with traditional threeport and four-port thoracoscopic surgery. However, this potential advantage is by no means certain (9). We suggest that chronic pain after thoracic surgery is also associated with the intercostal position of the surgery. When an incision is made below the 5 th rib, the inserted mirror and instrument cannot remain suspended vertically from the chest wall during the operation, in either an upper or lower lobectomy. The instrument and mirror's upwarp results in a sustained and intense squeeze on the incision and the ribs (10), and although the ribs are not propped open intercostal nerve damage has occurred indirectly. This is consistent with the fact that patients with traditional threeport VATS complain that chronic pain is most pronounced at the lowest incisions.

Since June 2014, we have performed VATS lobectomy through two $2.0-\mathrm{cm}$ intercostal muscle-sparing and minimally invasive incisions at a single intercostal site. The third or fourth intercostal segment is usually selected for upper or middle lobe lesions, and the fourth or fifth intercostal segment is usually selected for lower lobe lesions, which is higher than the traditional threeport or multi-port VATS incisions made below the fifth intercostal segment. In 2016, we reported that this surgical method could effectively avoid postoperative chronic pain compared with the traditional three-port VATS (10). This study retrospectively analyzed and followed up the 3- and 5 -year survival rates of NSCLC patients who underwent high-position single-intercostal two-port thoracoscopic lobectomy in our hospital from June 2014 to December 2018 and aimed to evaluate the safety and efficacy of this surgery. We present the following article in accordance with the STROBE reporting checklist (available at http://dx.doi. org/10.21037/jtd-20-3469).

\section{Methods}

\section{Data source}

From June 2014 to December 2018, a total of 474 NSCLC patients underwent lobectomy using high-position singleintercostal two-port VATS by the same one surgeon in the Department of Cardiothoracic Surgery, Hwa Mei Hospital, University of Chinese Academy of Sciences. Patient data were collected retrospectively by two investigators. This study was approved by the designated Ethics Committee of our hospital. The approval number is YJ-KYSBNBEY-2019-159-01. As this study was a retrospective study, patient informed consent was not required. All procedures performed in this study involving human participants were in accordance with the Declaration of Helsinki (as revised in 2013).

\section{Surgical procedures}

After anesthesia, the patient is given one-lung ventilation in the lateral decubitus position, and a small incision about $2.0 \mathrm{~cm}$ in the anterior and posterior axillary lines of the same intercostal space is made to retain the pectoral muscle (Figure 1A). This occurs without the ribs being propped open, operating only with a television display. The third or fourth intercostal segment is usually selected for upper lobe or middle lobe lesions, and the fourth or fifth intercostal segment is usually selected for lower lobe lesions. Incision protectors with an inner diameter of $2 \mathrm{~cm}$ are inserted into both incisions, and thoracoscopic instruments with a $10-\mathrm{mm}$ diameter and $30^{\circ}$ angle are used along with conventional thoracoscopic instruments. The surgeon and the assistant stand on the ventral side of the patient. Occasionally, the surgeon may operate in a seated position to relieve fatigue (Figure $1 B$ ). Usually, the mirror and the electrocoagulation hook or ultrasonic knife are placed in the 

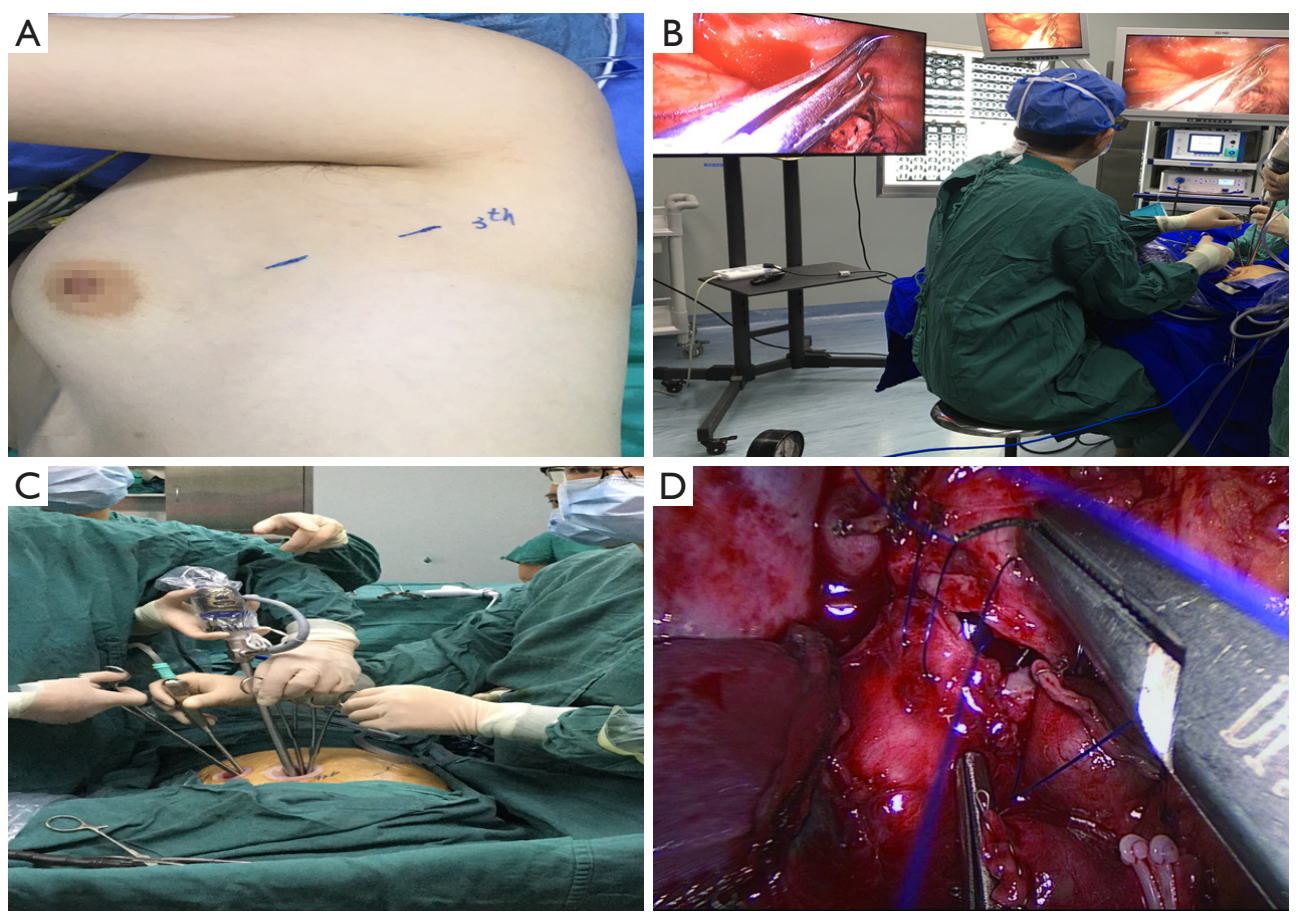

Figure 1 High-position single-intercostal two-port VATS. (A) Two incisions of approximately 2 cm are located at the same intercostal region's anterior and posterior axillary lines; (B) the surgeon may operate in a seated position to relieve fatigue; (C) the two incisions share the entrance and exit of the instrument and the mirror. During operation, the instrument, the mirror, and the chest wall are almost vertically suspended; (D) a right upper sleeve lobectomy is performed, and bronchoplasty is performed by continuous suture with a $4-0$ slide thread. VATS, video-assisted thoracoscopic surgery.

anterior axillary incision, and the mirror is located on the back of the instrument. However, it is also often changed to the posterior axillary incision to obtain a satisfactory visual field. Another surgical assistant (sometimes a nurse) stands behind the patient and extends lung grasping forceps from the incision into or at the front of the axilla and pulls the lung to help expose it. Usually, the lung grasping forceps of the assistant and the mirror are not in the same port, and the instruments of the left and right hand of the surgeon are not inserted into the same port (usually the suction device is held in the left hand, and the electrocoagulation hook or ultrasonic knife is held in the right hand) (Figure 1C). If a diagnosis of lung cancer is not ascertained before surgery, wedge resection of the mass should be performed first to make a definite diagnosis. When a lobectomy is performed, the first step of surgery is usually to break the horizontal or oblique fissure by tunneling with an endoscopic linear stapler. Additionally, in a lower lobectomy, the pulmonary vein, bronchus, and pulmonary artery are usually treated before the oblique fissure is broken. (I) The procedure for a left upper lobectomy is as follows: first, cut off the left upper lingual branch and the posterior apical branch of the artery, then cut off the anterior branch, the left upper pulmonary vein (breaking it off at the branch), dissect the para-bronchus lymph nodes, and finally cut off the left upper lobe bronchus. (II) The procedure for a right upper lobectomy is as follows: first, dissect the branches of the right upper pulmonary apex and anterior segment of the artery, then cut off the right upper lobe bronchus, dissect the para-bronchus lymph nodes, and finally cut off the right upper pulmonary vein and the right upper posterior segment of the lung artery together. If a right upper sleeve lobectomy is performed, the bronchus is finally treated (Figure 1D). (III) The procedure for a middle lobectomy is as follows: dissect the middle pulmonary artery first, then cut off the middle pulmonary vein, dissect the lymph nodes, and then cut off the middle bronchus. (IV) The procedure for a lower lobectomy is as follows: dissect the dorsal and basilar arteries first, then the lower lobe bronchus, and finally, the lower pulmonary vein. All bronchi resection (except sleeve lobectomy) and most pulmonary vascular ligation is performed using endoscopic linear staplers, 

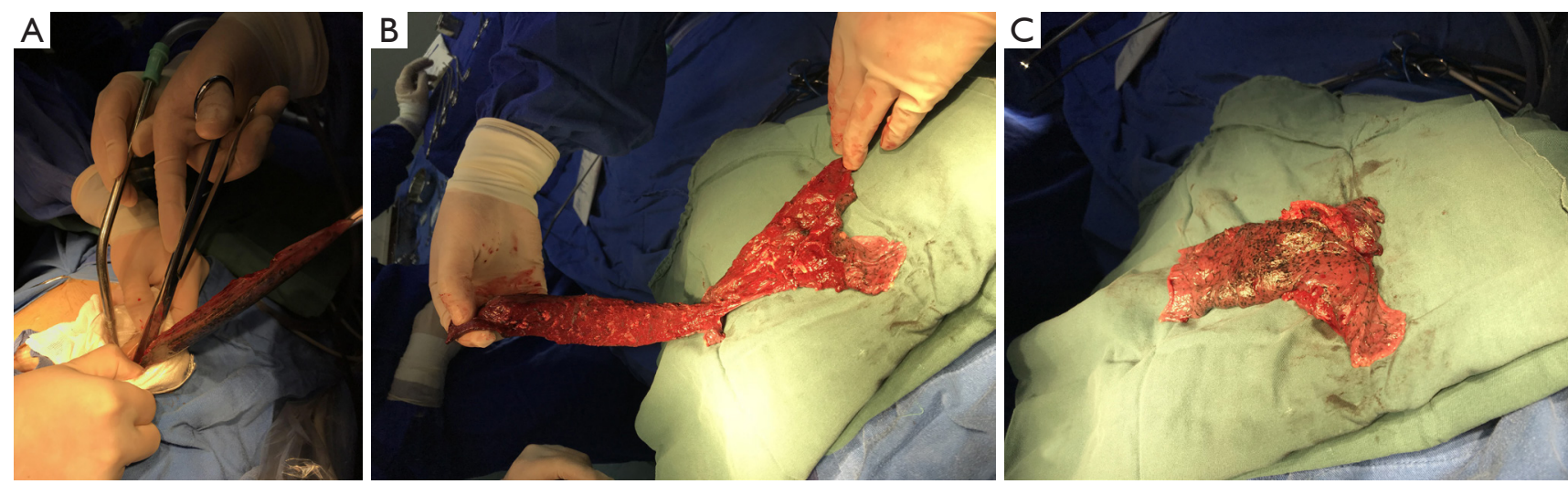

Figure 2 Removal of larger specimens. (A) The lung tissue is first put into the specimen bag (a large gallbladder bag) then carefully lifted and cut outside the incision and in the pocket. Finally, the lung tissue is cut into two before being removed. (B,C) The extracted lung can be wholly assembled into a whole lobe.

which are usually operated through the anterior axillary incision. Hem-o-lok clips are sometimes used to treat the left upper pulmonary vein, and a good visual field exposure is also achieved when the subcarinal lymph nodes (group 7) are dissected. Since the incision is only $2.0 \mathrm{~cm}$, it will be difficult to remove the specimen in patients with large lung lobes or tumors larger than $2 \mathrm{~cm}$. Our experience is that the specimen should always be taken from the incision in the anterior axillary line, where the intercostal space is widest. The incision protector is taken out first, and then the tissue is put into the specimen bag (a large gallbladder bag); outside the incision and in the pocket, the lung and tumor are carefully lifted while being cut, and the lung and tumor are cut into two before being removed. The extracted lung can be wholly assembled into a whole lobe (Figure 2), and then sent to the pathology department. At the end of the surgery, a $24 \mathrm{~F}-28 \mathrm{~F}$ chest tube is inserted into the anterior axillary incision. Endotracheal intubation is removed in all patients in the operating room.

\section{Postoperative management}

On the first day after the operation, the bedside chest radiograph is used to evaluate the degree of pulmonary recruitment maneuvers. If there are regular lung recruitment maneuvers and there is no bubble out of the chest flask drainage system with a forcible cough, the chest tube is removed. Patients are encouraged to get out of bed for functional exercise. Follow-up after discharge is completed in the outpatient clinic.

\section{Data collection}

General data and perioperative clinical parameters were collected from the case data, including age, gender, smoking history, complications, histological diagnosis, lesion location, degree of fissure development, pleural adhesion, intraoperative blood loss, duration of operation, incision location, postoperative complications, and survival data. Persistent pulmonary air leakage was defined as a sustained air leakage lasting 7 days or more. Overall survival (OS) of NSCLC patients was defined as the period from commencement of surgery to the patient's death. Relapsefree survival (RFS) was defined as the period from the day of surgery until tumor relapse was detected. Staging criteria for NSCLC were based on the staging system of the International Lung Cancer Research Association, $8^{\text {th }}$ edition. Fissure development was quantified according to the fissure development score (FDS) (11): Grade 0, good fissure development; Grade 1, fissure fusion degree $=0-30 \%$; Grade 2 , fissure fusion degree $=30-70 \%$; Grade 3, fissure fusion degree $>70 \%$. The FDS for the three fissure points was added and divided by 3 to get the fissure sum average (FSA). An FSA score of $0-1$ indicated good fissure development; if the score was greater than 1 , the pulmonary fissure was considered to be underdeveloped. The degree of pleural adhesion and the difficulty in separating pleural adhesion was evaluated according to the scoring system described by Oncel et al. (12): a score of $0-1$ indicated nil or mild pleural adhesion; a score of 2-4 indicated moderate pleural adhesion; a score of 5 indicated severe pleural adhesion. 
Table 1 General information of patients who underwent singleintercostal two-port thoracoscopic lobectomy

\begin{tabular}{lc}
\hline Characteristic & $\begin{array}{c}\text { Mean } \pm \text { standard } \\
\text { deviation or rate }(\%)\end{array}$ \\
\hline Gender & $168(35.4)$ \\
Male & $306(64.6)$ \\
Female & $59.7 \pm 10.8$ \\
Age (year) & \\
Smoking history & $355(74.9)$ \\
Never-smokers & $119(25.1)$ \\
Ever-smokers & \\
Comorbidities & $244(51.5)$ \\
None & $156(32.9)$ \\
Hypertension & $14(3.0)$ \\
Diabetes & $3(0.6)$ \\
Coronary heart disease & $4(0.8)$ \\
Chronic obstructive pulmonary disease & $2(0.4)$ \\
Asthma & $4(0.8)$ \\
Atrial fibrillation & $47(10.0)$ \\
Others & \\
\hline
\end{tabular}

\section{Statistical analysis}

All continuous variables are expressed as mean \pm standard deviation $(\bar{x} \pm s)$ and categorical variables are expressed as percentages. The 3- and 5-year survival rates and RFS of NSCLC patients were calculated using the Kaplan-Meier curve. All statistical analysis was performed with SPSS Statistics, version 19.0 (SPSS Inc., Chicago, IL).

\section{Results}

During the study period, a total of 474 patients underwent high-position single-intercostal two-port thoracoscopic lobectomy. Most of the patients were female nonsmokers, with an average age of $59.7 \pm 10.8$ years (Table 1 ). Hypertension and diabetes were the first and second comorbidities, respectively.

Intraoperative data is shown in Table 2: most lesions were located in the upper lobe of the right lung, and the distribution ratio of lesions in other lobes was similar. According to the lesions' location, most surgical incisions
Table 2 Intraoperative parameters of patients with singleintercostal two-port video-assisted thoracoscopic lobectomy

\begin{tabular}{lc}
\hline Characteristic & $\begin{array}{c}\text { Mean } \pm \text { standard } \\
\text { deviation or rate }(\%)\end{array}$ \\
\hline Incised location & $131(27.6)$ \\
The 3rd intercostals & $196(41.4)$ \\
The 4th intercostals & $147(31.0)$ \\
The 5th intercostals & \\
Excision extension & $77(16.2)$ \\
Upper lobe of left lung & $76(16.0)$ \\
Lower lobe of left lung & $177(37.3)$ \\
Upper lobe of right lung & $58(12.3)$ \\
Middle lobe of right lung & $75(15.9)$ \\
Lower lobe of right lung & $9(1.9)$ \\
Middle and lower lobe of right lung & $2(0.4)$ \\
The left lung & $160.9 \pm 44.9$ \\
The lesion size (mm) & $6.8 \pm 1.6$ \\
Pleural adhesions & $13.6 \pm 5.3$ \\
None or mild & $137(37.8$ \\
Modramberate & $22(4.7)$ \\
\hline
\end{tabular}

were located between the $3 \mathrm{rd}$ and 4th intercostal, followed by the 5 th intercostal. After entering the pleural cavity, the entire pleural cavity was initially explored. The oblique fissure and horizontal fissure were well developed in most patients, and approximately $42.0 \%$ of patients had differing degrees of pleural adhesions, of which six patients presented with dense pleural adhesions. Pneumonectomy was performed in two patients with lesions on the left side, and sleeve lobectomy was performed in seven patients. The average surgical time for all patients was $160.9 \pm 44.9 \mathrm{~min}$, the intraoperative blood loss was $67.1 \pm 48.3 \mathrm{~mL}$, and the 
average diameter of the lesion was $16.6 \pm 9.8 \mathrm{~mm}$. During surgery, a total of 31 patients were converted to three-port VATS or open surgery due to severe pleural adhesion $(n=25)$, hemorrhage $(n=4)$, and pulmonary fissure hypoplasia $(n=2)$. Among these, pleural adhesion was the most common reason for three-port VATS or thoracotomy (5.3\%).

Most of the patients recovered well after surgery, and the average postoperative hospital stay was $5.6 \pm 3.4$ days with an average period of $3.1 \pm 2.7$ days of chest tube drainage. Most patients were discharged after the removal of the chest tube and subsequent observation for 1 day. Persistent pleural leakage was the most common cause of delayed thoracic duct removal, with 20 patients developing this complication. Except for one patient with a history of coronary heart

Table 3 Postoperative data of patients

\begin{tabular}{lc}
\hline Characteristic & $\begin{array}{c}\text { Mean } \pm \text { standard } \\
\text { deviation or rate }(\%)\end{array}$ \\
\hline Postoperative hospital stay (days) & $5.6 \pm 3.4$ \\
Drainage time of chest tube (days) & $3.1 \pm 2.7$ \\
Complications & \\
None & $440(92.8)$ \\
Delayed air leakage & $20(4.2)$ \\
Delayed wound healing & $2(0.4)$ \\
Pneumonia & $5(1.1)$ \\
Pleural effusion & $2(0.4)$ \\
Chylothorax & $2(0.4)$ \\
Atrial fibrillation & $2(0.4)$ \\
\hline
\end{tabular}

disease who died of acute myocardial infarction on the 6th day after surgery, there were no deaths within 3 months after surgery (Table 3).

The average number of lymph nodes dissected in these patients was $13.6 \pm 5.3$, and the average number of lymph node dissection stations was $6.8 \pm 1.6$. The final pathological stages of IA, IB, IIA, IIB, and IIIA were $84.8 \%, 7.8 \%, 1.5 \%$, $2.1 \%$, and $3.8 \%$, respectively. The 3 - and 5 -year survival rates of patients at different pathological stages are shown in Table 4.

\section{Discussion and conclusions}

We performed VATS lobectomy through two $2.0-\mathrm{cm}$ intercostal muscle-sparing and minimally invasive incisions at a single intercostal site. We usually choose to make an incision in the upper intercostal segment for the following reasons: firstly, the upper intercostal segment is wider (our experience is that the third intercostal space is wider than the fourth and fifth intercostal spaces); secondly, the instrument, mirror, and chest wall can always maintain a nearly vertical suspended state, reducing the compression injury to the incision and the intercostal nerve. In addition, the intraoperative mirror and instrument can be changed between the two ports so that the top of the stapler and the outlet's side can be clearly seen in the field of vision. Intraoperative finger touch can also be used to determine the location of the pulmonary nodules (Figure 3). This procedure retains the advantage of single-port VATS by affecting only one intercostal space and avoids the disadvantages of single-port VATS surgery, such as instrument interference and poor visual field. Our high-

Table 4 Survival rates of patients with NSCLC at different pathological stages after single-intercostal two-port video-assisted thoracoscopic lobectomy

\begin{tabular}{|c|c|c|c|c|}
\hline Pathological stage & \multicolumn{2}{|c|}{ Overall survival (\%) } & \multicolumn{2}{|c|}{ Relapse-free survival (\%) } \\
\hline IA1 [188] & 99.0 & 99.0 & 98.1 & 92.9 \\
\hline IA2 [160] & 98.6 & 94.5 & 97.2 & 90.4 \\
\hline IA3 [54] & 96.3 & 87.5 & 94.3 & 84.2 \\
\hline IIA [7] & 85.7 & - & 80.0 & - \\
\hline IIB [10] & 66.7 & - & 56.3 & - \\
\hline IIIA [18] & 60.8 & 43.4 & 52.4 & - \\
\hline
\end{tabular}

NSCLC, non-small cell lung cancer. 


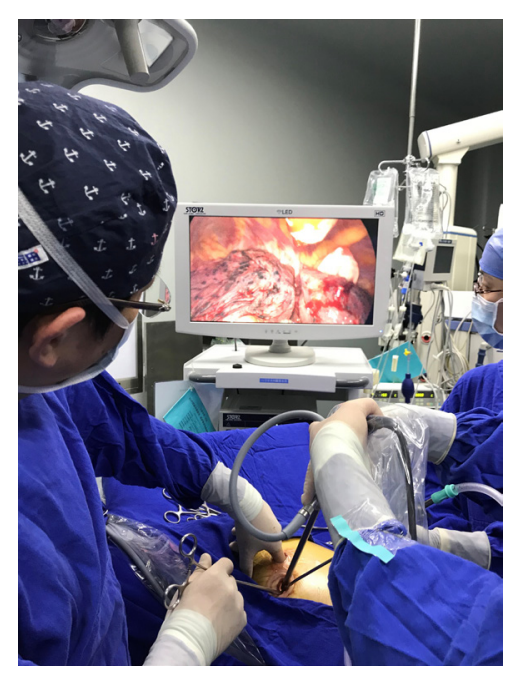

Figure 3 Intraoperative finger touch is used to determine the location of the pulmonary nodules.

position single-intercostal two-port VATS is suitable for all patients with well-developed fissures, and the upper lobe of the right lung and the lower lobe of the left lung are the most suitable sites for this surgical procedure. For patients with fissure hypoplasia, the first surgical step is usually to detach the horizontal or oblique fissure by tunneling with a cutting stapler. In this study, two patients underwent left superior lung lobectomy with poor oblique fissure development, and subsequent difficulty in tunneling resulted in conversion to three-port thoracoscopic surgery; in other words, a $1.5-\mathrm{cm}$ incision was added on the 7 th posterior intercostal axillary line for the use of a cutting stapler, and the oblique fissure was finally processed after the left upper pulmonary vein, bronchus and artery were severed. For complicated lobectomies, such as sleeve-type excision, the surgery time may be extensive, and the surgeon may operate in a seated position to relieve fatigue (Figure 1B).

In this study, among the 474 patients who underwent high-position single-intercostal two-port thoracoscopic lobectomy, 31 patients $(6.5 \%)$ were converted to open surgery or three-port thoracoscopic surgery during the operation. Of these, 23 patients were converted to open surgery, and eight patients were converted to three-port thoracoscopic surgery. Studies have shown a conversion rate of $1.6-10 \%$ for VATS surgery $(3,13-15)$. In this study, pleural adhesion was the most common reason for the conversion to open surgery, which mostly occurred in the early stage. The procedure we describe is also safe and feasible for complicated operations such as secondary surgery, sleeve lobectomy, and pneumonectomy. The posterior apical segment of the left superior pulmonary artery is considered a difficult vessel which is prone to rupture and bleed during surgery, whether open or endoscopic. In the past, when we performed traditional three-port surgery, every year we would encounter occasions when this blood vessel would rupture during separation, requiring a conversion to open surgery. However, this was not the case in this study and may be related to the fact that the surgical field and operating angle were better in the operation of a high-position single-intercostal two-port procedure than in the traditional three-port surgery.

Our average surgical time was $160.9 \pm 44.9 \mathrm{~min}$, which was less than the traditional porous method $(173 \mathrm{~min})$ reported in the literature (16) and some single port methods (3.6 h) (17), and similar to previous studies of two-intercostal two-port surgery $(163.4 \pm 68 \mathrm{~min})(14,15)$.

The incidence of postoperative complications was $7.2 \%$, which was significantly less than the $17 \%$ reported in the literature (14). Delayed air leakage was the most common complication $(4.2 \%)$, which is less than the previously reported incidence of $25 \%$ and $8 \%$ of different intercostal two-port and three-port surgery, respectively $(7,14)$. The patients' average postoperative hospital stay was 5.6 \pm 3.4 days, which is longer than the three-port or multi-port surgeries reported previously (14), but which may reflect the fact that most of our patients lived far from the hospital and had little opportunity for appropriate examination or treatment. Many patients were concerned that they would need to return for treatment if they felt unwell after discharge, so they often asked to extend their hospital stay.

This study's 3- and 5-year survival rates were similar to those reported in the literature for open surgery or VATS surgery $(13,18)$. The average number of lymph nodes dissected was $13.6 \pm 5.3$, which is higher than that of partial porous surgery (average 8.3) (18).

Insofar as surgical experience is concerned, the following should be noted: The surgeon in this study had extensive experience in three-port VATS surgery before this operation. At present, both of his assistants can perform this lobectomy independently. Neither of the two assistants had previous experience in three-port or multi-port VATS surgery. After an initial 20-30 supervised cases, we believe that a novice thoracic surgeon can master this surgical procedure. Right superior lobectomy is the easiest to master and is therefore recommended as the best procedure to learn first.

Because the surgical incision we used was small, some 
specimens needed to be cut with scissors before being removed. We routinely use the specimen bag and cut the lung lobe in the pocket and ensure that the pocket does not rupture (Figure 2). We have yet to come across a case of implantation of tumor cells into the incision.

In summary, compared with previous VATS procedures, high-position single-intercostal two-port thoracoscopic lobectomy for NSCLC had similar or even better outcomes in terms of surgical conversion rate, duration of surgery, and postoperative complications. The 3 - and 5-year survival rates of NSCLC patients were also similar to those reported in the literature. Therefore, we believe that this is a safe and effective surgical procedure and may have advantages in avoiding postoperative chronic pain.

This study has the following shortcomings: firstly, this is a single-center retrospective study, which cannot avoid the deficiency of selectivity bias. Secondly, since this was a single-arm observational study, we did not compare the data with open surgery or the traditional three-port or singleport surgery, and further prospective randomized controlled studies are needed to further elucidate the safety, efficacy, and potential advantages of this procedure in lobectomy for lung cancer and in avoiding postoperative chronic pain in patients.

\section{Acknowledgments}

Funding: This study was supported by Medical Health Science and Technology Project of Zhejiang Provincial Health Commission (Grant No. 2021430921).

\section{Footnote}

Reporting Checklist: The authors have completed the STROBE reporting checklist. Available at http://dx.doi. org/10.21037/jtd-20-3469

Data Sharing Statement: Available at http://dx.doi. org/10.21037/jtd-20-3469

Conflicts of Interest: All authors have completed the ICMJE uniform disclosure form (available at http://dx.doi. org/10.21037/jtd-20-3469). All authors report grants from Medical Health Science and Technology Project of Zhejiang Provincial Health Commission, during the conduct of the study. The authors have no other conflicts of interest to declare.

Ethical Statement: The authors are accountable for all aspects of the work in ensuring that questions related to the accuracy or integrity of any part of the work are appropriately investigated and resolved. All procedures performed in this study involving human participants were in accordance with the Declaration of Helsinki (as revised in 2013). This study was approved by the designated Ethics Committee of our hospital. The approval number is YJ-KYSB-NBEY-2019-159-01. As this study was a retrospective study, patient informed consent was not required.

Open Access Statement: This is an Open Access article distributed in accordance with the Creative Commons Attribution-NonCommercial-NoDerivs 4.0 International License (CC BY-NC-ND 4.0), which permits the noncommercial replication and distribution of the article with the strict proviso that no changes or edits are made and the original work is properly cited (including links to both the formal publication through the relevant DOI and the license). See: https://creativecommons.org/licenses/by-nc-nd/4.0/.

\section{References}

1. Onaitis MW, D'Amico TA. Lung cancer: minimally invasive approaches. In: Sellke FW, del Nido PJ, Swanson SJ. editors. Sabiston \& Spencer Surgery of the Chest. 8th ed. Philadelphia: Saunders-Elsevier, 2010:279-86.

2 Boffa DJ, Kosinski AS, Furnary AP, et al. Minimally invasive lung cancer surgery performed by thoracic surgeons as effective as thoracotomy. J Clin Oncol 2018;36:2378-85.

3 Long H, Tan Q, Luo Q, et al. Thoracoscopic surgery versus thoracotomy for lung cancer: short-term outcomes of a randomized trial. Ann Thorac Surg 2018;105:386-92.

4 Puri V, Patel A, Majumder K, et al. Intraoperative conversion from video-assisted thoracoscopic surgery lobectomy to open thoracotomy: a study of causes and implications. J Thorac Cardiovasc Surg 2015;149:55-62.e1.

5 Burfeind WR, D'Amico TA: Thoracoscopic lobectomy. Oper Tech Thorac Cardiovasc Surg 2004;9:98-114.

6 Rizk NP, Ghanie A, Hsu M, et al. A prospective trial comparing pain and quality of life measures after anatomic lung resection using thoracoscopy or thoracotomy. Ann Thorac Surg 2014;98:1160-6.

7 Sihoe AD, Au SS, Cheung ML, et al. Incidence of chest wall paresthesia after video-assisted thoracic surgery for primary spontaneous pneumothorax. Eur J Cardiothorac Surg 2004;25:1054-8. 
8 Macrae WA. Chronic pain after surgery. Br J Anaesth 2001;87:88-98.

9 Young R, McElnay P, Leslie R, et al. Is uniport thoracoscopic surgery less painful than multiple port approaches? Interact Cardiovasc Thorac Surg 2015;20:409-14.

10 Zhao G, Yang M, Xu X, et al. Single-intercostal twoport video-assisted thoracoscopic lobectomy and segmentectomy: experience with 200 cases and assessment of chronic pain. Chinese Journal of Thoracic Surgery 2016;3:100-6.

11 Lee S, Lee JG, Lee CY, et al. Pulmonary fissure development is a prognostic factor for patients with resected stage I lung adenocarcinoma. J Surg Oncol 2016;114:848-52.

12 Oncel M, Remzi FH, Senagore AJ, et al. Comparison of a novel liquid (Adcon-P) and a sodium hyaluronate and carboxymethylcellulose membrane (Seprafilm) in postsurgical adhesion formation in a murine model. Dis Colon Rectum 2003;46:187-91.

13 Xie D, Wang H, Fei K, et al. Single-port video-assisted thoracic surgery in 1063 cases: a single-institution experience†. Eur J Cardiothorac Surg 2016;49 Suppl

Cite this article as: Zhao G, Jiang $\mathrm{X}$, Wang F, Chu M, Zhang C, Zhao W, Yang M, Xu X, Zheng E, Ni J, Yang L. Lobectomy with high-position single-intercostal two-port video-assisted thoracoscope for non-small cell lung cancer is a safe and effective surgical procedure. $\mathrm{J}$ Thorac Dis 2020;12(12):7346-7354. doi: 10.21037/jtd-20-3469 1:i31-i36.

14 Swanson SJ, Herndon JE 2nd, D'Amico TA, et al. Videoassisted thoracic surgery lobectomy: report of CALGB 39802--a prospective, multi-institution feasibility study. J Clin Oncol 2007;25:4993-7.

15 Onaitis MW, Petersen RP, Balderson SS, et al. Thoracoscopic lobectomy is a safe and versatile procedure: experience with 500 consecutive patients. Ann Surg 2006;244:420-5.

16 Paul S, Altorki NK, Sheng S, et al. Thoracoscopic lobectomy is associated with lower morbidity than open lobectomy: a propensity-matched analysis from the STS database. J Thorac Cardiovasc Surg 2010;139:366-78.

17 Tam JK, Lim KS. Total muscle-sparing uniportal videoassisted thoracoscopic surgery lobectomy. Ann Thorac Surg 2013;96:1982-6.

18 Nwogu CE, D'Cunha J, Pang H, et al. VATS lobectomy has better perioperative outcomes than open lobectomy: CALGB 31001, an ancillary analysis of CALGB 140202 (Alliance). Ann Thorac Surg 2015;99:399-405.

(English Language Editor: D. Fitzgerald) 